\title{
Semantic Frame and EVT for Chinese EFL Learners
}

\author{
Fang Xu \\ Anhui University of Finance and Economics, Bengbu, China \\ Email: xf1206@126.com \\ Tao Li \\ Anhui University of Finance and Economics, Bengbu, China
}

\begin{abstract}
Vocabulary teaching has become the top priority in language teachers' agenda. Though a great amount of efforts have been plunged into vocabulary teaching, few amounts of achievements have been reached for lack of efficient vocabulary teaching model, particularly for Chinese EFL learners at university level. This paper, from the perspective of frame semantics, recommends semantic frame as an English vocabulary teaching model and finds that semantic frame will contribute to English vocabulary teaching in three aspects, namely word accumulation, word in long-term memory, and accumulation of pragmatic knowledge.
\end{abstract}

Index Terms — semantic frame, English vocabulary teaching, Chinese EFL learners

\section{INTRODUCTION}

English vocabulary teaching (EVT) plays an important role in English language Teaching (ELT). For a language learner, no matter how well he acquires grammar, how well he pronounces that language, he cannot, without vocabulary, carry out verbal communication with other people. It is mostly agreed that teaching vocabulary is the basis for the improvement in other language aspects. (Richards, 1976; Linnarud, 1986; Nation, 1990; Lewis, 1993; Schmitt \& McCarthy, 2002; Wolter, 2006; Xu, 2010)

New College English Curriculum Requirements (2004) issued by the Ministry of Education of the P.R.C. requires Chinese EFL learners at university level to have a command of 6,500 English words and 1,700 phrases. But correlated statistical data indicated that most non-English majors have a vocabulary of 5,000 and are not proficient at them. The insufficient acquisition of vocabulary considerably hinders their mastering of the five skills of listening, speaking, reading, writing and translating prescribed in the college curriculum for English teaching.

This paper, based on Frame Semantics, addresses the question of how to make Chinese EFL learners at university level improve their English vocabulary with high efficiency. By examining the mechanism of vocabulary acquisition and semantic frame, I intend to solve the following research questions:

1) Why semantic frame facilitates EVT for Chinese EFL learners?

2) In what aspects semantic frame benefits English EVT for Chinese EFL learners?

\section{LITERATURE REVIEW}

\section{A. Current Situation in EVT}

Vocabulary is a fundamental component of a language system. Krashen (1989) argued that a large vocabulary is essential for mastery of a language, and that lack of vocabulary is a major problem. McCarthy (1990) furthered this idea that no matter how well the student learns the grammar, no matter how successfully he masters the sound of a second language, without vocabulary to express a wide range of meanings, communication in that language cannot take place in any meaningful way. Vermeer (1992) also stated that knowing words is the key to understanding and being understood. Grammatical knowledge does not make sure of great proficiency in a language and the bulk of learning a new language largely consists of learning new vocabulary.

A solid vocabulary is necessary in every stage of language learning. The role of vocabulary in communication calls for continuing vocabulary learning. As Candlin (1988) asserted the study of vocabulary is at the heart of language teaching in terms of organization of syllabus, the evaluation of learner performance and the provision of learning resources. The majority of second language learners take vocabulary as their top priority because they know that the possession of an adequate and appropriate vocabulary is essential for their mastery of that language and effective communication. Thus, we have sound reason to believe that vocabulary functions as the core of a language.

In recent years, more attention has been paid to the vocabulary teaching. More and more scholars are taking interest in EVT and accomplished many encouraging results. (Schmitt, 2000; Hatch \& Brown, 2001; Allen, 2002; Schmitt \& McCarthy, 2002; Hiebert\& Kamil, 2005; Pigada \& Schmitt, 2006; Nation, 2008; Khan, 2008; Graves, 2009) However, 
some EFL teachers consider EVT as an isolated task. So students are required just to repeat the new words until they can memorize them. Some others think EVT requires a process of related sub-tasks: when students first come across a new word, they are encouraged to guess its meaning and usage from available clues, or look it up in the dictionary, or take notes on the margins, between the lines, or on particular vocabulary notebooks, and then read the new word repeatedly until they reach a state that they can produce them by intuition. All in all, in order to accomplish the task of EVT, one should spare no efforts to highlight the improvement in both remembering words and the ability to use them automatically in a wide range of language contexts when the need arises. (McCarthy, 1984)

And many findings recently indicated that lexical problems often interfere with communication and communication breaks down when people do not use the proper words. In addition, experienced EFL teachers become to be aware that the importance of vocabulary is in language production. They noticed that even though they had devoted much time to vocabulary teaching, the results had been disappointing. Sometimes, after months or even years of learning English, students still cannot use words in an appropriate way and even cannot recall what had been restored in their memory in a certain situation. That is to say, they cannot produce language by intuition because they haven't exerted vocabulary in their deep memory. If they have, they can extract them from their mind naturally. Therefore, the mastery of the basic linguistic skills in English is the dependent of adequate and solid vocabulary storage.

Dissatisfied with the discouraging result of learning English vocabulary without real discourse situation, some EFL learners are encouraged to try the lexical approach, i.e. a vocabulary-based approach, which emphasizes word combinations. The lexical-approach has proved to be a productive and promising approach for vocabulary teaching based on the theory of semantic field. Through this approach, EFL learners can memorize new words with efficiency and comprehend the exact meanings of words, which is very important and meaningful to them even though it is not easy to accustom them to the lexical-approach within a short period of time. However, there still appear some difficulties such as to find a specific semantic field for each word in the process of vocabulary learning.

For many of EFL teachers and researchers in China, our perspective on teaching vocabulary was greatly influenced by the top-down, naturalistic, and communicative approaches of the 1970s and 1980s. The emphasis was implicit, incidental learning of vocabulary. We were taught the importance of encouraging second language students to look for clues in context, use monolingual dictionaries (which has already been proved not necessary for beginners), and avoid defining words or glossing texts with their bilingual equivalents. Textbooks emphasize inferring word meaning from context as the primary vocabulary skill. Although exposure to a word in a variety of contexts is vital to understanding the detailed senses of a word, providing incidental encounter with words is just one method to ease vocabulary acquisition.

The arguments for not simply focusing on implicit instruction to facilitate second language vocabulary acquisition originate from a number of potential problems associated with inferring words from context. First of all, acquiring vocabulary mainly through guessing words in context is likely to be a very slow process. (Sternberg, 1987) Considering that many Chinese EFL learners have a limited time to acquire a body of words, it is not perhaps the most efficient way to approach the task. Secondly, word meaning guess is an error-finding process. Recent studies have shown students seldom guess the correct meanings. (Pressley, Levin \& McDaniel, 1987; Kelly, 1990) Students, particularly those with low-level proficiency in English, are often discouraged with this approach and it is difficult to recover the possible damage by incorrect guess. In addition, even when students are trained to use flexible reading strategies to guess words in context, their comprehension may still be at a low level due to insufficient vocabulary knowledge. (Haynes \& Baker, 1993) What's more, if not most importantly, guessing from context often result in easy-come-easy-go state. So we can clearly point out the ineffectiveness of just using implicit vocabulary instruction and the need to accompany it with a much stronger word level or bottom-up approach than had been previously advocated.

In a word, EVT is a fundamental part of English teaching and how to improve EVT mode to cater for the mechanism of vocabulary acquisition is essential to a successful EFL teacher.

\section{B. Characteristics of Chinese EFL Learners}

Chinese EFL learners at university level invest much energy into English vocabulary acquisition because English is a compulsory course in every institute of higher education and students in many universities are even required to achieve a passing score in College English Test in order to attain degree.

However, it is still very difficult for them to do well in such a job. They are a large group of people with limited access to authentic English materials and limited access to English native speakers, and they tend to learn a new word without natural English circumstances. As a result, they often have difficulties in the memory and the comprehension of vocabulary, so they can neither easily grasp the exact meanings of a word in different contexts, nor can they use words correctly or naturally in conversation or composition.

Some related statistic data indicated that mistakes in vocabulary that Chinese EFL learners at university level made amount to over $50 \%$ of the total errors. The more advanced the Chinese EFL learners are, the fewer grammatical errors but comparatively more vocabulary mistakes they make. The founding also showed that Chinese EFL learners have a limited number of productive vocabularies. Li Rui (2007), after a survey among non-English majors, found that vocabulary problems are the highest compared with other problems, such as grammar problems, cultural problems, pronunciation problems. And most frequently mentioned among vocabulary problems are the limited amount of words, wrong usage of certain lexical items, and incorrect understanding of word meanings. One of his interviewees said "I 
always use the same words to express different ideas, because I can't remember other words learned before, even if I remember some of them, I'm not sure of their usage." His two surveys clearly showed that there is an urgent need for EFL teachers to help those Chinese EFL learners expand vocabulary size and improve the strong memory of vocabulary so as to use them in a proper way.

And as we all know, classroom activities which demand deeper processing can be time-consuming in terms of four classes only once a week for non-English majors in Chinese universities. So it is surely not possible for these Chinese EFL learners at university level to acquire all English words required in the classroom. A solution to this contradiction to acquire a large vocabulary in relatively limited time is to find an effective EVT model and to help these learners learn how to acquire English vocabulary on their own with efficiency.

To help improve EVT for Chinese EFL learners at university level, this paper is seeking semantic frame as the guideline for the establishment of an EVT model.

\section{APPLiCATION OF Frame Semantic In EVT}

\section{A. Theory of Frame Semantics}

Frame semantics is a theory that extends linguistic semantics to encyclopedic knowledge developed by Charles $\mathrm{J}$. Fillmore (1982), and it is a further development of his case grammar (1968). The key point is that one can't understand the meaning of a single word without access to all the significant knowledge that relates to that word.

Fillmore illustrates this by offering a frame of commercial transaction. This frame includes a person interested in exchanging money for goods (the Buyer), a person in want of exchanging goods for money (the Seller). The Buyer did or could acquire (the Goods), and the money acquired by the seller (the Money). Under this framework, it's possible to say that the verb BUY focuses on the acts of the Buyer with respect to the Goods, back grounding the Seller and the Money; that the verb SELL focuses on the acts of the Seller with respect to the Goods, back grounding the Buyer and the Money; that the verb PAY focuses on the acts of the Buyer with respect to both the Money and the Seller, back grounding the Goods, and so on, with such verbs as SPEND, COST, CHARGE, and a number of other outsiders to these.

Such description was to point out that no one can be considered to know the meanings of these verbs who did not know the details of the kind of frame which provided the background information and motivation for the categories that these words represent. Its essence lies in that one would not be able to understand the word sell without knowing anything about the circumstances of commercial transfer, which at least involves, among other things, a seller, a buyer, goods, money, the relations between the seller and the goods and the money, the relation between the money and the goods, the relation between the buyer and the goods and the money and the like. Thus, a word activates a frame of semantic information relating to the specific concept it refers to.

Although the concept of frame in various fields within cognitive psychology appears to have origins quite independent of linguistics, a semantic frame in this theory is defined as "any system of concepts related in such a way that to understand any one of them you have to understand the whole structure in which it fits; when one of the things in such a structure is introduced into a text, or into a conversation, all of the others are automatically made available." (Fillmore, 1982, p.111)

Frames are based on people's recurring experiences. So the frame of commercial transaction is based on recurring experiences of commercial transaction. Words not only emphasize individual concepts, but also ascertain a specific perspective in which the frame is viewed. For example sell is viewed from the perspective of the seller in the situation. The only way in which people can really be said to understand the use to which these meaning-bearing elements are being put in natural utterances is to be familiar with those experiences and institutions and to know why such experiences and institutions provided people with reasons to create the categories expressed by the words.

"Frame semantics offers a particular way of looking at word meanings, as well as a way of characterizing principles for creating new words and phrases, for adding new meanings to words, and for assembling the meanings of elements in a text into the total meaning of the text." (Fillmore, 1982, p.111) Based on the idea of semantic frame and supported by corpus evidence, the Berkeley FrameNet project is created as an on-line lexical resource for English language with its aim documenting the range of semantic and syntactic combinatory possible valences of each word in each of its senses through computer-assisted annotation of illustrations and automatic tables and display of the annotation results. FrameNet can display not only the annotation of the word but also the relations between corresponding words under the frame. Figure $1^{(1)}$ is a sample output from FrameGrapher available at FrameNet website.

\footnotetext{
(1) http://framenet.icsi.berkeley.edu/index.php?option=com_content\&task=blogcategory\&id=0\&Itemid=82
} 


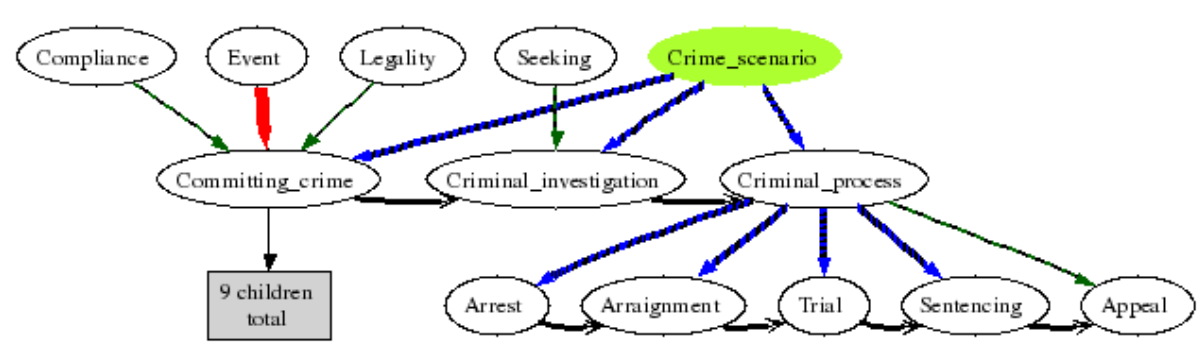

Figure 1 Sample output from FrameGrapher

We can see clear from the above description that semantic frame and its applicable product FrameNet can be very conducive to EVT. With such EVT model, its essential idea that to understand one single word means to understand all the important knowledge that relates to that word and that a different perspective shows a different focus is surely exposing the mechanism of vocabulary acquisition. And it is obvious that vocabulary teaching shall meet that demand.

\section{B. Semantic Frame and EVT}

Since vocabulary acquisition occupies such a crucial position in second language acquisition and the main problem for the Chinese EFL learners at university level to improve their English is the shortage of vocabulary, the unclear memory of words and improper use of them, an effective solution to help these university Chinese EFL learners enlarge their vocabulary and acquire English vocabulary with efficiency shall be the focus in the EVT.

The basic idea of semantic frame lies in the following three points. Firstly, the only way in which people can truly be said to understand the use is to understand the whole structure in which it fits (Fillmore, 1982); secondly, when one of the things in a frame is introduced into a text, or into a conversation, all of the others in this frame are automatically made available; and thirdly, "the only way in which people can truly be said to understand the use to which these meaning-bearing elements are being put in actual utterances is to understand those experiences and institutions and to know why such experiences and institutions gave people reasons to create the categories expressed by the words." (Fillmore, 1982, p. 132)

These three points can enlighten EVT in at least three ways. Firstly, semantic frame can be an effective EVT model to help Chinese EFL learners at university level to enlarge their vocabulary because to learn one word means to learn all related words within the same frame. Secondly, semantic frame will help Chinese learners at university level to keep words in the long-term memory because it has already been proved that it is easier to memorize a new word with fore grounded information. And thirdly, semantic frame will help them to produce proper and influent language in conversation or composition because a semantic frame assembles those words or phrases within a certain topic, which will surely help those university Chinese EFL learners retrieve proper words on certain occasion.

Semantic Frame and Word Enlargement: Some corresponding research has already shown that small vocabulary size is an obstacle to language production. An effective way to help enlarge vocabulary is to employ semantic frame during vocabulary teaching. For non-English majors, EFL teachers shall highlight the role of semantic frame in EVT.

Semantic frame, in one aspect, is also a word net that collects almost all related words. If an EFL teacher wants to teach a new English word, he needs to teach the background of this word, including its related words. And from different perspective, different words would be highlighted. For example, if someone wants to know the word communicator in the semantic frame COMMUNICATION, he will have to know the word communicate, communication, topic, medium and so on. By teaching one word, he lets the learners get full access to other related words and phrases, which will surely help them to acquire other new words or keep the words that they already knew to a deeper memory. What's more, if he encounters a new word in a frame, this word, so called the element of the frame, may lead him to another frame since frames are also connected by certain node (some words belong to different frames, thus they function as node connecting deferent frames).

Semantic Frame and Words in Long-term Memory: We all know that cognitive processing involves three kinds of memory, the short-term memory, the working memory, and the long term memory. The short term memory refers to that people have the ability to remember a limited number of information for a short period of time up to a few seconds. Memory of this sort involves keeping series of numbers like phone number as long as you repeat it. Concentrating on words long enough to perform operations on them is the function of working memory. Unlike working memory with limited capacity and no permanent content, long-term memory has a larger capacity and information is stored durably. Cognitive processing system plays an important role in deciding whether new information comes into long-term memory. The interaction of working and long-term memory is also vital for language production. So for the Chinese EFL learners at university level, their failure to possess a large English vocabulary does not lie in lack of efforts in vocabulary acquisition but in failure to find a good acquisition mode to move word information to long-term memory.

Exposure to a word in context and understanding its semantic relations with corresponding language component are crucial to full understanding its meaning. "People pick up much of their vocabulary knowledge from context." (Schmitt \& McCarthy, 2002, p. 69) Krashen (1989) argues that "language learners acquire vocabulary and spelling most efficiently by receiving comprehensible input while reading" (p. 440) and "successful language learning results from comprehensible input as the essential external ingredient coupled with a powerful internal language acquisition device" 
(p. 440). That is to say, in order to keep vocabulary in long-term memory so as to retrieve them proficiently and use them properly in conversation and composition, one shall try to acquire words in context.

Semantic frame not only provides the background information about a word, but also its semantic relations with other components. If an EFL teacher wants to help learners acquire the word charge in the frame COMMERCIAL TRANSACTION, he would try to make them understand the situation in which a transaction is taking place. And he will also help them find its semantic relations with other components in this frame, like seller, buyer, and money and so on. Such kind of information will surely promote his memory of the word charge.

And from different perspective, different component will be highlighted. The word charge in the frame COMMERCIAL TRANSACTION is to highlight the process of taking money from the perspective of sellers. The element money in this frame is highlighted from the perspective of transaction means. This is also to say every element in a frame shall be strengthened from certain perspective. And those words that are profiled will leave the learner deep impression, which is also helpful to long-term memory of those words.

Semantic Frame and Accumulation of Pragmatic Knowledge: Language is used for human communications. So the ultimate goal of EVT is to help learners organize those lexical units into correct discourses which will promote proper communication. Factors such as topic, style, register, the status of the speaker and hearer will have great influence on the proper use of vocabulary. If someone lacks of pragmatic competence of a word, even with a good command of linguistic knowledge or that word, he will probably use that word in an inappropriate way, hence causing the communication failure.

Semantic frame in some sense is a word collection within the same topic. In such a way, these participants in a semantic frame build a potential natural communication situation in which factors that involved in proper communication are displayed probably in a hidden way. Chinese EFL learners can discover the proper use of the word from the participant role of a word in this frame and its relations with other components. Take the sub frame COMMUNICATION-MANNER as an example, if an EFL teacher wants to teach the word chatter, it is necessary for him to teach the learners in what situation this word is used, the style of conversation, the relations between the speaker and the hearer. Without helping the learners know this, the teacher hasn't fulfilled his task to help the learners acquire such word.

And semantic frame is a web-like schema in which words are semantically related. Chinese EFL learners would use words appropriately if teachers could help them establish those links and build up those relations between each unit of word information. When EFL learners are required to draw on their background information, they could reestablish the connection between a word and other lexical units already known. The link is created, and proper language production takes place.

In addition, both EVT theory and semantic frame emphasize the real world experience. The role of world knowledge in learning from context is of special significance for second language learners. (Schmitt \& McCarthy, 2002, p. 80) Semantic frames are categorized based world knowledge. In other words, semantic frame, to some extent, reflects world experience, including the real natural communication situation. This is obviously enlightening to EVT.

\section{CONCLUSION}

Because vocabulary is the very foundation of learning a language, improving students' vocabulary knowledge has become a priority in language teaching. For Chinese EFL learners at university level, the difficulty in the process of vocabulary acquisition lies in lack of an efficient acquisition model that could help enlarge vocabulary, keep longer memory, and produce properly with such vocabulary in communication or writing. To solve this problem is an EFL teacher's top priority. To establish a scientific and efficient EVT model is surely conducive to Chinese EFL learners.

This paper, from the perspective of frame semantics, recommends semantic frame as a basis for EVT model and explores in what way semantic frame will help EVT. Finally, this paper concluded that semantic frame will contribute to EVT in three aspects, namely vocabulary enlargement, long-term memory of vocabulary and proper use of them. However, empirical work needs to be conducted to justify its validity. And this constitutes an interesting topic for future study.

\section{ACKNOWLEDGMENTS}

This work was supported in part by a grant from Anhui University of Finance and Economics (ACJYYB2011147).

\section{REFERENCES}

[1] Allen, V. (2002). Techniques in teaching Vocabulary. Shanghai Foreign Language Education Press.

[2] Andrews, S. J. (2009). Educational Background as Predictor of Lexical Richness Among Libyan and Saudi Arabian ESL Students. University of Pittsburgh.

[3] Dupuy, B. \& S. Krashen. (1993). Incidental vocabulary acquisition in French as a foreign language. Applied Language Learning 4, 55-63.

[4] Ellis, R. \& X. He. (1999). The roles of modified input and output in the incidental acquisition of word meanings. Studies in Second Language Acquisition 21: 285-301. 
[5] Ellis, R. (1995). Modified Oral Input and the Acquisition of Word Meanings. Applied Linguistics 16: 409-441.

[6] Engber, C. (1995). The relationship of lexical proficiency to the quality of ESL compositions. Journal of Second Language Writing 4: 139-155.

[7] Farstrup, A. \& S. Samuel (2008). What Research Has to Say about Vocabulary Instruction. International Reading Association.

[8] Fillmore C.J., C.R. Johnson \& M.R.L. Petruck (2003). Background to Framenet. International Journal of Lexicography 3: 235-250.

[9] Fillmore, C. J. \& B. Atkins (1992). Towards a frame-based organization of the lexicon: The semantics of RISK and its neighbors. In Lehrer, A \&E. Kittay (Eds). Frames, Fields, and Contrast: New Essays in Semantics and Lexical Organization. Hillsdale: Lawrence Erlbaum Associates.

[10] Fillmore, C. J. (1968). The case for case. In Bach \& Harms (Eds). Universals in Linguistic Theory. Holt, Rinehart, and Winston.

[11] Fillmore, C. J. (1982) Frame Semantics. In The Linguistic Society of Korea (Eds), Linguistics in the Morning Calm. Seoul: Hanshin Publishing Co,

[12] Fillmore, C. J., C. Wooters \& Collin F. Baker. (2001). Building a large lexical databank which provides deep semantics. the 15th Pacific Asia Conference on Language, Information and Computation, Hong Kong.

[13] Gliozzo, A. M. (2006). Semantic Domains and Linguistic Theory. The LREC 2006 workshop. Genova, Italy.

[14] Graves, M. (2009). Essential Readings on Vocabulary Instruction. International Reading Association.

[15] Hatch, E. \& C. Brown (2001). Vocabulary, Semantics and Language Education. Foreign Language Teaching and Research Press.

[16] He, Chunmei. (2006). Vocabulary Acquisition with Pragmatic Awareness: A Study on the Factors Influencing Pragmatic Competence in Vocabulary Acquisition. Sichuan University.

[17] Hiebert, E. \& M. Kamil (2005). Teaching and learning vocabulary: bringing research to practice. Routledge.

[18] Khan, M. (2008). Teaching English Vocabulary For Special Purpose. Uppal Publishing House.

[19] Krashen, S. D. (1989). We Acquire Vocabulary and Spelling by Reading: Additional Evidence for the Input Hypothesis. Modern Language Journal 73:440-446.

[20] Lewis, M. (1993). The Lexical Approach, the state of ELT a new way forward. Boston: Thomson Publishing.

[21] Li Rui. (2007). Cognitive Meaning Construction and English Vocabulary Acquisition. Harbin Engineering University.

[22] Lin, C.-c. (1997). Semantic Network for Vocabulary Teaching. Journal of National Taiwan Normal University: Humanities and Social Science 42: 43-54.

[23] Linnarud, M. (1986). Lexis in composition: A performance analysis of Swedish learner's written English. CWK Gleerup.

[24] Lomicka, L. (1998). To gloss or not to gloss: An investigation of reading comprehension online. Language learning and Technology 2: 41-50.

[25] Machalias, R. (1991). Semantic networks in vocabulary teaching and their application in the foreign language classroom. Babel: Journal of the Australian Modern Language Teachers' Associations 3: 19-24.

[26] Nation, L. S. P. (1990). Teaching and learning vocabulary. Newbury House.

[27] Nation, L. S. P. (2008). Teaching Vocabulary-Strategies and Techniques. Heinle ELT.

[28] Peng, Jianqiong. (2007). Strategies of English Vocabulary Teaching. Journal of Chengdu University, 8:22-24 to 42.

[29] Petruck, M. R. L. \& H. C. Boas. (2003). All in a Day’s Week. In E. Hajičová, A. Kotěšovcová \& Mírovský, J. (Eds). Proceedings of the 17th International Congress of Linguists. CD-ROM. Matfyzpress.

[30] Petruck, M. R. L. (1996). Frame Semantics. In J. Verschueren, J-O. Östman, J.Blommaert \& C. Bulcaen (Eds.), Handbook of Pragmatics. John Benjamins.

[31] Pigada, M. \& N. Schmitt (2006). Vocabulary acquisition from extensive reading: A case study. Reading in a Foreign Language 18: 1-28.

[32] Richards, J. C. (1976). The Role of Vocabulary Teaching. TESOL Quarterly 1:77-89.

[33] Schmitt, N. \& M. McCarthy. (2002). Vocabulary: Description, acquisition, and pedagogy. Cambridge university press.

[34] Schmitt, N. (2000). Vocabulary in Language Teaching. Cambridge University Press.

[35] Wang, Qinghua. (1998). On the Vocabulary Size of University Chinese EFL Learners. Foreign Language World 2: 23-27.

[36] Waring, R. \& M. Takaki. (2003). At what rate do learners learn and retain new vocabulary from reading a graded reader?. Reading in a Foreign Language 15: 130-163.

[37] Wilkins, D.A. (1972). Linguistics in Language Teaching. London, Edward Arnold.

[38] Wolter, B. (2006). Lexical Network Structures and L2 Vocabulary Acquisition: The Role of L1 Lexical/Conceptual Knowledge. Applied Linguistics 4:741-747.

[39] Xu, Xiaohui. (2010). The Effects of Glosses on Incidental Vocabulary Acquisition in Reading. Journal of Language Teaching and Research 2: 117-120.

Fang Xu was born in Huangshan, China in 1981. She received her M.A. degree in English Language and Literature from Shanghai International Studies University in 2009. She is currently a teacher of English in the School of Foreign Languages, Anhui University of Finance and Economics, Bengbu, China. Her research interests include Second Language Acquisition and Foreign Language Teaching, Translation Studies.

Tao Li was born in Dangshan, China in 1980. He received his M.A. degree in Linguistics and Applied Linguistics from Guangdong University of Foreign Studies in 2009. He is currently a teacher of English in the School of Foreign Languages, Anhui University of Finance and Economics. His research interests cover corpus-based EVT, Translation Studies, Dictionary making. 